To Maega | Jurnal Pengabdian Masyarakat

Februari 2022, Vol.5, No.1, hal, 34-43

$\operatorname{ISSN}(P): 2622-6332 ; \operatorname{ISSN}(E): 2622-6340$

http://www.ojs.unanda.ac.id/index.php/tomaega

\title{
Pendampingan dan Penguatan Anak Usia Sekolah di Desa Panyampa dengan Pembelajaran Berbasis Literasi melalui Program Kelas Pesisir
}

\author{
Arlinda Puspita Sari ${ }^{1}$, M. Irfan ${ }^{1 *}$, Firdaus ${ }^{1}$ \\ 1 Program Studi Pendidikan Biologi, Fakultas Keguruan dan Ilmu Pendidikan, Universitas \\ Sulawesi Barat \\ *Correspondent Email: irfan.razak@unsulbar.ac.id
}

Article History:

Received: 31-10-2021; Received in Revised: 12-11-2021; Accepted: 16-12-2021

DOI: http://dx.doi.org/10.35914/tomaega.v5i1.939

\begin{abstract}
Abstrak
Desa Panyampa terletak di Kecamatan Campalagian, Kabupaten Polewali Mandar, Provinsi Sulawesi Barat. Di Desa Panyampa terdapat banyak anak yang putus sekolah karena membantu orangtunya bekerja. Selain itu banyak pula anak-anak yang masih bersekolah, namun mengalami kendala dalam beradaptasi dengan pembelajaran dari rumah. Kelas Pesisir merupakan program yang dirancang agar anak-anak pesisir di Desa Panyampa, baik yang putus sekolah maupun yang masih bersekolah memiliki wadah untuk belajar bersama serta membangun budaya literasi sejak dini. Kegiatan Kelas Pesisir diikuti oleh 43 orang peserta didik yang dibimbing oleh tim PKM, mahasiswa Prodi Pendidikan Biologi Universitas Sulawesi Barat, serta pengurus sanggar Sipaqmarasa. Pengurus sanggar merupakan pemuda dan pemudi asli Desa Panyampa yang juga memiliki keinginan untuk membangun budaya literasi bagi anakanak di Desanya. Oleh karena itu, para pengurus sanggar inilah yang nantinya akan melanjutkan program-program Kelas Pesisir yang telah kami rintis. Pelaksanaan Kelas Pesisir dilakukan sebanyak dua kali dengan konsep yang dirancang agar pembelajaran berlangsung dalam suasana yang menyenangkan. Hasil evaluasi angket menunjukkan bahwa mitra merasa sangat setuju (91,67\%) bahwa pelaksanaan Kelas Pesisir ini sesuai dengan kebutuhan anak di Desa Panyampa dan disajikan dengan berbagai metode yang menarik.
\end{abstract}

Kata Kunci: Anak Usia Sekolah, Kelas Pesisir, Literasi, Panyampa, Pembelajaran

\begin{abstract}
Panyampa Village was located in Campalagian District, Polewali Mandar Regency, West Sulawesi Province. In Panyampa Village, there were many children who drop out of school because they help their parents to work. In addition, there was also many children who was still in school, but faced the learning difficulties in adapting to learning from home. Kelas Pesisir is a program designed for coastal children in Panyampa Village, both dropouts and those who are still in school have a place to learn together and build a literacy culture from an early age. The activity of Kelas Pesisir was attended by 43 students who were guided by the PKM team, students of the Biology Education Study Program, University of West Sulawesi, and member of the Sipaqmarasa studio. The member of Sipaqmarasa studio was young people from Panyampa Village who also have a desire to build a literacy culture for children in their village. Therefore, they will also continue the programs of Kelas Pesisir that we have pioneered. The implementation of
\end{abstract}


the Kelas Pesisir was carried out twice which was designed with the concept of learning taking place in a pleasant atmosphere. The results of the questionnaire evaluation showed that partners strongly agreed (91.67\%) that the implementation of the Kelas Pesisir was in accordance with the needs of children in Panyampa Village and was presented with various interesting methods.

Key Word: School Age Children, Kelas Pesisir, Literacy, Panyampa, Learning

\section{Pendahuluan}

Panyampa merupakan salah satu Desa yang terletak di Kecamatan Campalagian, Kabupaten Polewali Mandar, Provinsi Sulawesi Barat. Desa Panyampa merupakan daerah pesisir pantai yang lokasinya tidak begitu jauh dari kota Kecamatan. Desa Panyampa terdiri atas 4 dusun, yakni dusun Gusung, dusun Sengkae, dusun Lurae, dan dusun Morro. Sebagian besar warga desa Panyampa berprofesi sebagai nelayan. Kondisi masyarakat setempat sebagian besar masih tergolong dalam keluarga prasejahtera (Pandang et al., 2019). Beberapa keluarga diantaranya merupakan pasangan muda yang menikah di bawah usia pernikahan yang ditetapkan oleh Kementerian Agama. Sehingga beberapa pasangan muda ini masih tinggal dengan orangtuanya.

Berdasarkan penelitian yang dilakukan oleh Fakultas Keguruan dan Ilmu Pendidikan Universitas Sulawesi Barat bekerjasama dengan Badan Penelitian dan Pengembangan Daerah Sulawesi Barat, diperoleh informasi bahwa Desa Panyampa merupakan salah satu desa di Sulawesi Barat yang memiliki angka Indeks Pembangunan Manusia (IPM) rendah dari aspek kesehatan, pendidikan, dan sosial ekonomi (Pandang et al., 2019). Penelitian IPM yang dilakukan oleh Fakultas Keguruan dan Ilmu Pendidikan, Universitas Sulawesi Barat menemukan fakta bahwa Desa Panyampa merupakan salah satu desa yang memiliki jumlah bayi stunting dan angka putus sekolah yang cukup tinggi. Berdasarkan hasil wawancara, tingginya angka putus sekolah disebabkan banyak anak usia sekolah yang membantu pekerjaan orangtuanya sebagai nelayan. Hal ini tidak terlepas dari paradigma masyarakat yang telah melekat bahwa pendidikan yang tinggi tidak diperlukan. Anak-anak cukup melanjutkan pekerjaan orangtuanya sebagai nelayan untuk memenuhi kebutuhan hidupnya. Hayun (2019) menyatakan bahwa, orang tua dengan tingkat pendidikan dan ekonomi yang rendah memiliki persepsi bahwa pendidikan formal bukanlah suatu hal yang penting. Pendidikan dibutuhkan sebatas untuk keperluan mendapatkan pekerjaan. Hal ini pula yang terjadi di Desa Panyampa, yakni orangtua menganggap bahwa pendidikan ditempuh untuk mendapatkan pekerjaan, sehingga apabila anak mereka sudah bisa membantu pekerjaan sebagai nelayan, maka pendidikan tersebut tidak lagi dianggap perlu dilanjutkan.

Selain anak putus sekolah, di Desa Panyampa juga terdapat banyak anak usia sekolah yang kesulitan berdaptasi dengan proses pembelajaran dari rumah. Sama halnya di daerah lain, selama masa pandemi, sekolah di Desa Panyampa 
juga menyelenggarakan proses pembelajaran secara daring. Pembelajaran daring sebagian besar berbasis tekhnologi untuk mempermudah pelaksanaannya (Salsabila et al., 2020) yakni dengan memanfaatkan sejumlah perangkat dan platform untuk menyampaikan materi pelajaran. Selain itu pembelajaran daring yang dilakukan pada tingkat sekolah dasar membutuhkan bimbingan dari orang tua siswa dalam pelaksanaannya (Dewi, 2020). Berdasarkan hasil observasi, hal ini tidak berjalan optimal di Desa Panyampa sebab orang tua dengan tingkat ekonomi yang rendah tidak dapat memenuhi kebutuhan tekhnologi anaknya dalam melaksanakan pembelajaran. Keluarga yang memiliki lebih dari dua anak namun hanya memiliki satu gawai tentu akan kesulitan menjalankan pembelajaran secara daring. Belum lagi, kurang terbimbingnya anak oleh orangtua selama pembelajaran daring sebab orangtua sibuk bekerja.

Berdasarkan analisis permasalahan tersebut, kami sebagai bagian yang berkecimpung erat dengan dunia pendidikan tergerak untuk melaksanakan salah satu tri dharma perguruan tinggi yakni pengabdian kepada masyarakat. Pengabdian yang kami lakukan adalah dengan membentuk Program Kelas Pesisir bagi anak-anak usia sekolah dan anak putus sekolah di Desa Panyampa. Kegiatan ini tentu diharapkan dapat berkelanjutan, sehingga kami menjalin kerjasama dengan pemerintah desa setempat dan salah satu Sanggar yang bergerak dalam bidang literasi yang ada di Desa Panyampa. Pemuda-pemudi pengurus Sanggar tersebut diharapkan dapat menjadi kader yang akan melanjutkan programprogram Kelas Pesisir ke depannya.

\section{Metode}

Program Kelas Pesisir telah dilakukan sejak bulan Juni sampai Bulan Juli 2021 yang dimulai dari tahap koordinasi, persiapan, hingga pelaksanaan. Pelaksanaan Kelas Pesisir sendiri dilakukan sebanyak dua kali yakni pada tanggal 4 Juli 2021 bertempat di Pantai Barane, Dusun Morro, Desa Panyampa. Kelas Pesisir tahap kedua dilaksanakan pada tanggal 12 Juli 2021, bertempat di Aula Kantor Desa Panyampa. Program Kelas Pesisir ini melibatkan 43 orang peserta didik yang berasal dari berbagai dusun yang ada di Desa Panyampa, pengurus Sanggar Sipaqmarasa, serta mahasiswa Program Studi Pendidikan Biologi yang bertindak sebagai tenaga pengajar.

Adapun metode pelaksanaan kegiatan Program Kelas Pesisir dilakukan berdasarkan tahapan berikut: 
1. Tahap pertama yaitu melakukan observasi dan koordinasi dengan pemerintah desa serta pihak-pihak lain yang terlibat.

2. Tahap kedua yaitu persiapan yakni menyusun kurikulum yang akan diterapkan pada peserta didik. Kurikulum meliputi tujuan, gambaran metode, dan materi yang akan diberikan kepada peserta didik (Lazwardi, 2017). Kurikulum disusun berdasarkan kebutuhan pembelajaran peserta didik yang diperoleh dari informasi rentan usia dan tingkatan kelas peserta didik yang ada di Desa Panyampa. Selain itu dilakukan persiapan bahan ajar dan media pembelajaran yang menarik dan informatif, seperti buku berhitung dan membaca yang disertai gambar, serta beberapa alat peraga yang dapat membantu proses pembelajaran.

3. Tahap ketiga yakni pelaksanaan yaitu memberikan pembelajaran kepada peserta didik dengan suasana belajar yang menyenangkan, fun, dan diselingi dengan games. Peserta didik dibagi ke dalam beberapa kelompok yang disesuiakan dengan usia dan tingkatan kelas. Masing-masing kelompok dibimbing oleh mahasiswa Program Studi Pendidikan Biologi dan pengurus Sanggar Sipaqmarasa.

4. Tahap keempat yaitu evaluasi dengan memberikan angket kepuasan kepada pengurus Sanggar Sipaqmarasa selaku pihak yang bekerjasama dengan tim dalam pelaksanaan Program Kelas Pesisir dan pihak yang nantinya akan melanjutkan Program Kelas Pesisir ini.

\section{Hasil dan Pembahasan}

Kelas Pesisir merupakan program yang kami susun sebagai upaya memberikan wadah bagi anak-anak pesisir di Desa Panyampa, Kecamatan Campalagian, Polewali Mandar untuk bisa belajar bersama. Program ini kami susun dengan melihat banyaknya anak putus sekolah di Desa Panyampa akibat bekerja sebagai nelayan untuk membantu orangtua. Selain itu, selama masa pandemi anak-anak juga mengalami berbagai kesulitan belajar baik dari segi fasilitas maupun pembimbingan. Melalui Program Kelas Pesisir ini, kami berupaya menciptakan wadah belajar bagi anak-anak dengan membangun suasana belajar yang menyenangkan agar peserta didik tidak bosan dan lebih mudah memahami pelajarannya. Suasana belajar yang menyenangkan akan membantu peserta didik untuk fokus dalam menerima pelajaran serta akan meningkatkan motivasi belajarnya (Nasution \& Syaf, 2018). Penelitian yang dilakukan Febriyanti (2014) menyatakan bahwa terdapat korelasi $(r=0,799)$ antara suasana lingkungan belajar dengan motivasi belajar siswa kelas 5 SDN III Kota Bengkulu. Hal ini menunjukkan pentingnya membangun suasana belajar yang menyenangkan agar peserta didik termotivasi dan semangat dalam belajar.

Pembentukan Kelas Pesisir diawali dengan koordinasi bersama Kepala Desa Panyampa dan Kepala Dusun Morro (Gambar 1) yang kemudian mengarahkan 
kami untuk berkolaborasi dengan salah satu sanggar yang ada di Desa tersebut. Sanggar yang dimaksud adalah Sanggar Sipaqmarasa yang saat ini juga mulai melakukan kegiatan literasi bagi anak-anak pesisir di Desa Panyampa. Hal ini sesuai dengan harapan kami yakni berkolaborasi dengan pemuda di Desa agar kedepannya program Kelas Pesisir ini dapat terus berlanjut. Para pengurus sanggar Sipaqmarasa memiliki keinginan besar untuk membangun literasi bagi anak-anak di desanya, namun memiliki keterbatasan berupa kurangnya buku bacaan yang mereka miliki untuk anak-anak. Hal ini menjadi peluang kerjasama bagi kami yang juga ingin membantu pendidikan anak-anak pesisir di Desa Panyampa utamanya pendidikan berbasis literasi.

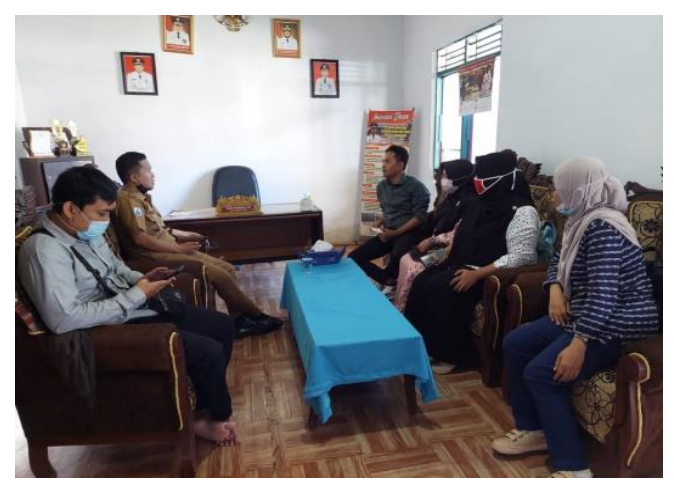

Gambar 1. Koordinasi dengan Kepala Desa Panyampa

Tabel 1. Daftar sebaran peserta didik Kelas Pesisir Desa Panyampa

\begin{tabular}{|c|c|c|c|c|}
\hline No & \multicolumn{2}{|c|}{ Kategori Identitas } & Jumlah & Persentase (\%) \\
\hline \multirow[b]{2}{*}{1} & \multirow{2}{*}{ Jenis Kelamin } & a. Laki-laki & 25 orang & 58,2 \\
\hline & & b. Perempuan & 18 orang & 41,8 \\
\hline \multirow{5}{*}{2} & \multirow{5}{*}{ Alamat } & a. Dusun Morro & 17 orang & 39,5 \\
\hline & & b. Panyampa & 18 orang & 41,8 \\
\hline & & c. Dusun Sengkae & 3 orang & 6,9 \\
\hline & & d. Baurung & 3 orang & 6,9 \\
\hline & & e. Kenje & 2 orang & 4,6 \\
\hline \multirow{8}{*}{3} & \multirow{8}{*}{$\begin{array}{c}\text { Tingkatan } \\
\text { Kelas }\end{array}$} & a. Kelas 1 & 5 orang & 11,6 \\
\hline & & b. Kelas 2 & 4 orang & 9,3 \\
\hline & & c. Kelas 3 & 8 orang & 18,6 \\
\hline & & d. Kelas 4 & 5 orang & 11,6 \\
\hline & & e. Kelas 5 & 11 orang & 25,5 \\
\hline & & f. Kelas 6 & 5 orang & 11,6 \\
\hline & & g. $\quad$ Kelas 7 & 4 orang & 9,3 \\
\hline & & h. Tidak Sekolah & 1 orang & 2,3 \\
\hline
\end{tabular}

Kelas Pesisir tahap pertama dilaksanakan pada tanggal 4 Juli 2021 di Pantai Barane, Dusun Morro, Desa Panyampa. Kegiatan ini dihadiri oleh 43 anak dari berbagai usia dan tingkatan pendidikan. Beberapa diantaranya masih bersekolah namun kegiatan pembelajarannya tidak berlangsung optimal akibat pandemi. Beberapa lainnya merupakan anak-anak yang putus sekolah. Pembelajaran 
dilakukan secara interaktif dan menarik serta diselingi dengan games menarik (Gambar 2). Anak-anak dikelompokkan berdasarkan usia dan tingkat pendidikan, kemudian tiap kelompok dibimbing oleh tim PKM, mahasiswa Prodi Pendidikan Biologi, dan pengurus sanggar Sipaqmarasa.

Tabel 1 menunjukkan data sebaran peserta didik program Kelas Pesisir. Sebagian besar merupakan peserta didik pada tingkat Sekolah Dasar. Beberapa diantaranya tidak melanjutkan sekolah ke tingkat berikutnya. Berdasarkan pengamatan kami selama Kelas Pesisir berlangsung, masih banyak anak yang belum fasih membaca dan juga belum lancar menulis. Kami memberikan metode pembelajaran membaca dan menulis menggunakan gambar dan disertai contoh langsung. Menurut Nugraheni et al. (2019), penggunaan buku cerita yang disertai gambar dengan warna dan karakter yang menarik dapat meningkatkan ketertarikan dan minat anak untuk mempelajari buku tersebut. Hal ini secara tidak langsung akan meningkatkan motivasi anak untuk dapat membaca isi buku tersebut. Ditambahkan oleh Yono et al. (2021) bahwa pemberian informasi berupa edukasi kepada peserta didik dapat membantu meningkatkan pemahamannya mengenai suatu objek. Edukasi yang kami berikan melalui pendidikan literasi diharapkan dapat meningkatkan pengetahuan anak di Desa Panyampa.

Kelas Pesisir tahap kedua dilaksanakan di Aula Desa Panyampa pada tanggal 12 Juli 2021 dan dihadiri oleh beberapa anak yang sama dengan tahap pertama serta beberapa peserta yang baru (Gambar 3). Sama halnya dengan kegiatan Kelas Pesisir tahap pertama, pada tahap kedua pun anak-anak dibagi ke dalam beberapa kelompok berdasarkan kategori usia dan tingkatan kelas. Pada tahap kedua ini, selain pembelajaran membaca, menulis, dan berhitung, anak-anak juga diajarkan beberapa doa-doa harian serta kesenian. Proses dikemas semenarik mungkin dengan diselingi games agar anak-anak tidak bosan. Ratnawati \& Asniawati (2020) melakukan pengabdian serupa yakni memberikan selingan games dan cerita dalam proses belajar peserta didik tingkat SD dan SMP untuk meningkatkan motivasi belajarnya. Salah satu games yang diberikan berupa pertanyaan mengenai pengetahuan umum.
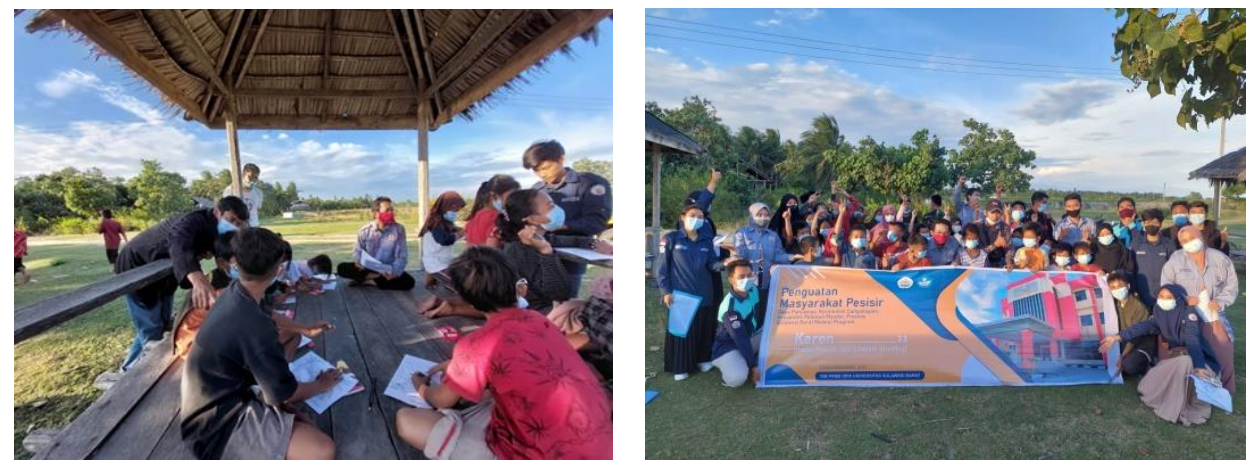

Gambar 2. Kegiatan Kelas Pesisir Tahap 1 

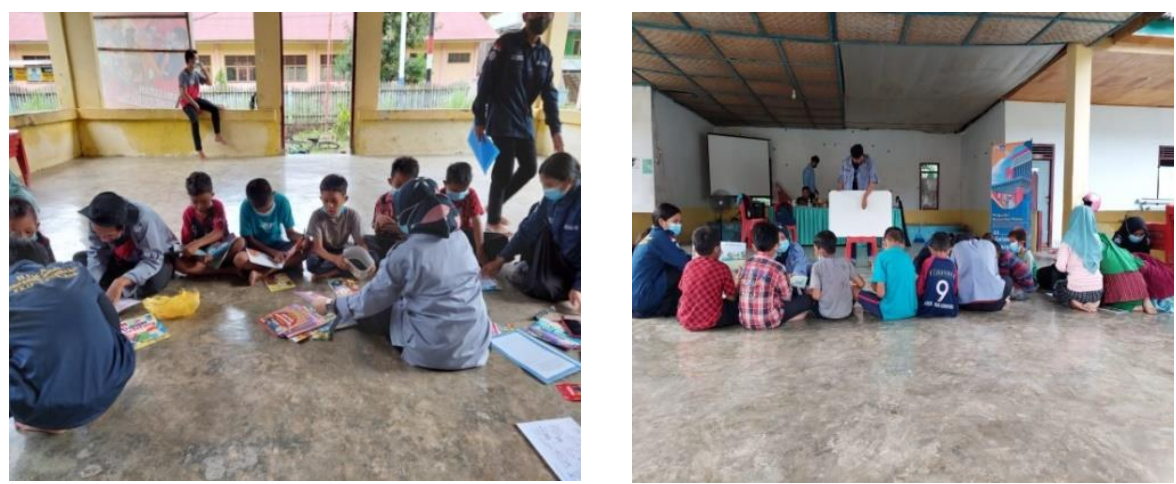

Gambar 3. Proses Belajar Mengajar Kelas Pesisir Tahap 2

Pada tahap evaluasi, kami memberikan angket kepuasan kepada pengurus Sanggar Sipaqmarasa sebagai mitra yang bekerjasama dengan kami dan nantinya akan menuruskan program Kelas Pesisir ini. Tabel 2 menunjukkan hasil analisis angket kepuasan pelaksanaan Kelas pesisir.

Tabel 2. Hasil analisi angket kepuasan pelaksanaan Kelas Pesisir

\begin{tabular}{|c|c|c|c|c|c|}
\hline \multirow{3}{*}{ No. } & \multirow{3}{*}{ Pernyataan } & \multicolumn{4}{|c|}{ Jumlah Penilaian } \\
\hline & & 4 & 3 & 2 & 1 \\
\hline & & SS & $\mathbf{S}$ & TS & STS \\
\hline 1 & $\begin{array}{l}\text { Kegiatan yang dilakukan sesuai dengan tema/ } \\
\text { judul pengabdian }\end{array}$ & 2 & 1 & & \\
\hline 2 & $\begin{array}{c}\text { Kegiatan yang dilakukan sesuai dengan kebutuhan } \\
\text { peserta kelas pesisir }\end{array}$ & 3 & & & \\
\hline 3 & $\begin{array}{l}\text { Sarana yang diberikan sesuai dengan kebutuhan } \\
\text { peserta kelas pesisir }\end{array}$ & 3 & & & \\
\hline 4 & $\begin{array}{l}\text { Personil/ anggota kegiatan pengabdian kepada } \\
\text { masyarakat menjalin komunikasi dan koordinasi } \\
\text { yang baik dengan mitra }\end{array}$ & 3 & & & \\
\hline 5 & $\begin{array}{l}\text { Personil/anggota yang terlibat dalam kegiatan } \\
\text { pengabdian masyarakat memberikan pelayanan } \\
\text { sesuai dengan kebutuhan peserta kelas pesisir }\end{array}$ & 3 & & & \\
\hline 6 & $\begin{array}{l}\text { Kegiatan kelas pesisir memberikan pengalaman } \\
\text { belajar baru bagi peserta kelas pesisir }\end{array}$ & 2 & 1 & & \\
\hline 7 & $\begin{array}{l}\text { Kegiatan kelas pesisir membantu program literasi } \\
\text { kami }\end{array}$ & 3 & & & \\
\hline 8 & $\begin{array}{l}\text { Jika kegiatan ini diselenggarakan kembali, kami } \\
\text { bersedia untuk berpartisipasi/terlibat }\end{array}$ & 3 & & & \\
\hline & Jumlah & 22 & 2 & & \\
\hline & Persentase (\%) & 91,67 & 8,33 & & \\
\hline
\end{tabular}

Keterangan: SS= Sangat Setuju; S= Setuju; TS=Tidak Setuju; STS= Sangat Tidak Setuju

(C)To Maega / Jurnal Pengabdian Masyarakat. This is an open access article under the CC BY-SA 4.0 license (https://creativecommons.org/licenses/by-sa/4.0/). 
Berdasarkan hasil analisis angket, ketiga orang responden menyatakan sangat setuju bahwa kegiatan Kelas Pesisir ini sesuai dengan kebutuhan anak-anak yang ada di Desa Panyampa. Kebutuhan utama dari anak-anak pesisir tersebut adalah pembelajaran yang terbimbing utamanya untuk membaca dan berhitung. Suastika (2018) menyatakan bahwa membaca dan menulis merupakan kemampuan yang menjadi dasar bagi peserta didik untuk dapat menguasai kemampuan pada tingkat berikutnya. Oleh karena itu diperlukan perhatian dan pembimbingan khusus oleh guru atau pendidik untuk menguatkan kemampuan dasar tersebut.

Para pengurus sanggar juga menyatakan sangat setuju bahwa sarana yang kami sediakan sesuai dengan kebutuhan peserta Kelas Pesisir. Kami menyediakan beberapa buku bacaan bergambar yang berisi pesan-pesan moral. Kami berharap anak-anak tidak hanya fasih membaca tapi juga dapat mempelajari pesan moral maupun etika yang penting untuk mereka terapkan dalam kehidupan sehari-hari. Menurut Nurmanita et al. (2017), karakter-karakter yang ditemukan anak di dalam buku bacaannya dapat menjadi pembelajaran dan contoh bagi anak tersebut. Sehingga dengan membaca buku cerita bergambar berisi pesan moral dan etika akan membantu anak untuk fasih membaca sekaligus meniru perilaku baik dari karakter pada buku tersebut.

Hasil analisis angket juga diperoleh informasi bahwa pengurus sanggar Sipaqmarasa merasa sangat setuju bahwa program Kelas Pesisir ini memberikan pengalaman belajar baru bagi anak-anak pesisir di Desa Panyampa dan tentunya membantu program literasi sanggar Sipaqmarasa. Biasanya kegiatan literasi yang dilakukan sanggar hanya sebatas memberikan bacaan kepada anak-anak. Namun melalui program Kelas Pesisir ini, kami memberikan berbagai macam metode pembelajaran dengan berbagai alat peraga yang membantu peserta didik untuk belajar. Pemberian metode disesuaikan dengan tema pembelajaran. Menurut Juniyati et al. (2015) pembelajaran tematik merupakan pembelajaran yang dirancang berdasarkan tema tertentu menggunakan berbagai metode yang sesuai dengan tujuan agar siswa dapat memahami konsep dari beberapa bidang studi secara terpadu. Sedangkan alat peraga merupakan alat yang dapat membantu membangun pemahaman konsep pada peserta didik (Suliani, 2020). Konsep dan metode ini dapat pengurus sanggar teruskan pada pelaksanaan Kelas Pesisir berikutnya.

Secara umum, pelaksanaan Kelas Pesisir ini berjalan dengan baik dan memuaskan bagi mitra, dilihat dari persentase kepuasan pada pilihan sangat setuju sebesar 91,67\% dan pilihan setuju sebesar 8,33\%. Hal ini menunjukkan bahwa program yang kami laksanakan membawa manfaat tidak hanya bagi peserta didik, tapi juga memberikan manfaat bagi sanggar Sipaqmarasa yang akan melanjutkan program ini. Manfaat tersebut tidak hanya berupa pengalaman dalam memberikan pembelajaran kepada peserta didik, tapi juga manfaat dari bertambahnya bahan 
ajar berupa buku dan alat peraga yang kami titipkan kepada sanggar untuk dapat digunakan dalam proses pembelajaran anak-anak pesisir di Desa Panyampa.

\section{Kesimpulan}

Kelas Pesisir merupakan program yang dirancang untuk menyediakan wadah belajar bagi anak-anak pesisir di Desa Panyampa, Kecamatan Campalagian, Polewali Mandar, Sulawesi Barat, baik untuk anak yang putus sekolah maupun anak yang masih sekolah namun mengalami kendala dalam belajar selama masa pandemi. Program ini diselenggarakan bekerjasama dengan pemerintah Desa Panyampa dan sanggar Sipaqmarasa yang merupakan pemuda dan pemudi asli Desa Panyampa yang memiliki keinginan untuk mengembangkan literasi di daerahnya. Para pengurus sanggar inilah yang nantinya akan meneruskan program-program dan kurikulum yang dirancang untuk Kelas Pesisir. Pelaksanaan Kelas Pesisir dilakukan dengan memberikan berbagai metode pembelajaran yang telah dirancang dalam kurikulum dan disesuaikan dengan kebutuhan peserta didik. Hasil evaluasi kepuasan mitra menunjukkan bahwa para pengurus sanggar Sipaqmarasa sangat setuju bahwa program Kelas Pesisir ini sesuai dengan kebutuhan anak di Desa Panyampa. Begitupun dengan metode dan alat peraga yang digunakan selama pembelajaran juga sesuai dengan tingkatan kelas dan kebutuhan peserta didik.

\section{Ucapan Terimakasih}

Ucapan terimakasih kami sampaikan kepada LPPM dan PM Universitas Sulawesi Barat yang telah mendanai kegiatan ini melalui dana Hibah DIPA Universitas Sulawesi Barat 2021 pada Program Kemitraan Masyarakat Stimulus.

\section{Daftar Pustaka}

Dewi, W.A.F. (2020). Dampak Covid-19 Terhadap Implementasi Pembelajaran Daring Di Sekolah Dasar. Jurnal Ilmu Pendidikan, 2(1), 55-61. https://edukatif.org/index.php/edukatif/index

Febriyanti, A. (2014). Hubungan Suasana Lingkungan Belajar Dengan Motivasi Belajar Siswa Kelas V Sd Negeri Gugus III Kota Bengkulu. [Skripsi] Bengkulu: Universitas Bengkulu

Hayun, S. (2019). Persepsi Masyarakat Tentang Pentingnya Pendidikan Formal (Studi Kasus di Desa Pilowo Kecamatan Morotai Selatan Kabupaten Pulau Morotai). JMP Online, 3(8), 1092-1104.

Juniyati, L., Ummah, H., Nisa, Z., Desi, A.M., Aini, S., \& Maha, P.W. (2015). Penerapan Variasi Metode Pembelajaran Dalam Penanaman Karakter Siswa Sd Muhammadiyah 8 Surabaya Melalui Program Lesson Study. Didaktis, 15(2), 1-12.

Lazwardi, D. (2017). Manajemen Kurikulum Sebagai Pengembangan Tujuan Pendidikan. Al-Idarah: Jurnal Kependidikan Islam, 7(1), 99-112. 
Nasution, I.N., \& Syaf, A. (2018). Hubungan Iklim Kelas Terhadap Motivasi Belajar Siswa SMK Abdurrab Itto. PSYCHOPOLYTAN (Jurnal Psikologi), 1(2), 98-110.

Nugraheni, I., Harsiati, T., \& Qohar, A. (2019). Media Buku Cerita untuk Meningkatkan Kemampuan Membaca dan Menulis Siswa Kelas IV Sekolah Dasar. Jurnal Pendidikan: Teori, Penelitian, Dan Pengembangan, 4(3), 322-329. http://journal.um.ac.id/index.php/jptpp/

Nurmanita, T., Harsiati, T., \& Suyono. (2017). Cerita Anak sebagai Sarana Pendidikan Karakter di Sekolah Dasar. Prosiding TEP \& PDs Transformasi Pendidikan Abad 21, 7(9), 1100-1105.

Pandang, A., Hajati, K., \& Sapiah, S. (2019). Analisis Faktor-Faktor yang Mempengaruhi Indeks Pembangunan Manusia Provinsi Sulawesi Barat. [Laporan Kegiatan] Badan Penelitian dan Pengembangan Provinsi Sulawesi Barat.

Ratnawati, E., \& Asniawati, A. (2020). Pemberian Motivasi Melalui Cerita Dan Games Untuk Menumbuhkan Minat Belajar Anak Usia SD Dan SMP. DIMASEJATI, 2(2), 2004-2013.

Salsabila, U.H., Irna, S.L., Haibati, L.K., Puji, L.A., \& Ayuning, A. (2020). Peran Teknologi Dalam Pembelajaran Di Masa Pandemi Covid-19. AlMutharahah: Jurnal Penelitian Dan Kajian Sosial Keagamaan, 17(2), 188198. https://doi.org/10.46781/al-mutharahah.v17i2.138

Suastika, N. (2018). Problematika Pembelajaran Membaca Dan Menulis Permulaan Di Sekolah Dasar. ADI WIDYA: Jurnal Pendidikan Dasar, 3(1), 57-64. http://ejournal.ihdn.ac.id/index.php/AW

Suliani, M. (2020). Persepsi Siswa Terhadap Penggunaan Alat Peraga dalam Pembelajaran Matematika. SJME (Supremum Journal of Mathematics Education), 4(1), 92-100.

Yono, R. R., Mumpuni, A., Permana, A., \& Ubaedillah, U. (2021). Pelatihan Drama Bagi Siswa SMP Negeri 1 Songgom. To Maega: Jurnal Pengabdian Masyarakat, 4(3), 304-315. https://doi.org/10.35914/tomaega.v4i3.846 